\title{
A EDUCAÇÃO FINANCEIRA COMO UM DIFERENCIAL NAS DECISÕES DE CONSUMO E INVESTIMENTO DOS ESTUDANTES DO CURSO DE CIÊNCIAS CONTÁBEIS NA GRANDE JOÃO PESSOA
}

\author{
FINANCIAL EDUCATION AS A DIFFERENCE IN CONSUMER AND INVESTMENT \\ DECISIONS OF ACCOUNTING SCIENCES COURSE OF STUDENTS IN BIG JOÃO \\ PESSOA
}

\author{
Thamirys de Sousa Correia \\ thamirys_correia@hotmail.com \\ Universidade Federal da Paraíba
}

\author{
Wenner Glaucio Lopes Lucena \\ wdlucena@yahoo.com.br \\ Universidade Federal da Paraíba
}

\author{
Kalyne Amaral Di Lorenzo Gadelha \\ kalyne amaral@hotmail.com> \\ Universidade Federal da Paraíba
}

\begin{abstract}
RESUMO: Sabendo-se que para os que objetivam uma saúde financeira, conhecimentos, ferramentas adequadas para lidar melhor com o dinheiro, bem como não prejudicar o orçamento ao final do mês, a Educação Financeira é importante nas decisões de consumo e investimento, a presente pesquisa tem como intuito descrever o nível de educação financeira dos jovens estudantes de Ciências Contábeis. Quanto à metodologia, foi realizada a aplicação de questionários aplicados a alunos iniciantes e concluintes de Contabilidade, em cinco instituições de ensino da grande João Pessoa, quatro particulares e uma pública, sendo utilizado o programa estatístico SPSS versão XX para tabular os dados. Constatou-se que as mães com maior instrução acadêmica auxiliam para uma melhor educação financeira dos seus filhos, respondido pelo teste de Mann-Whitney U. Os respondentes em uma percentagem considerável optaram pela estabilidade nos retornos dos investimentos em detrimento aos riscos. E dos que afirmaram não possuir dívidas, muitos alunos demonstram se preocupar com a qualidade e preços dos produtos que adquirem, bem como preferir a estabilidade da poupança em detrimento aos financiamentos.
\end{abstract}

Palavras-chave: Educação Financeira; Consumo e Investimento; Decisões Financeiras.

ABSTRACT: Knowing that for those who aim for a financial health, useful knowledge, appropriate tools to better handle the money and not harm the budget to the end of the month, the Financial Education is essential in consumption and investment decisions, this research has the intention to describe the level of financial education of young students of Accounting. Regarding the methodology, the questionnaires was conducted applied to beginners and Accounting graduates in five educational institutions of the great João Pessoa, four private and one public, using the SPSS statistical program to tabulate the data. It was found that mothers with higher academic instruction help for better financial education of their children, answered by the Mann-Whitney $U$ test Respondents in a considerable percentage opted for stability in investment returns over the risks. And of those who said that they have debts, many students demonstrate to worry about the quality and prices of the products they purchase and prefer the stability of savings over the financing.

Key Words: Financial Education; Consumption and Investment; Financial decisions. 


\section{INTRODUÇÃO}

A necessidade de adquirir conhecimentos financeiros, não é mais só inerente aos profissionais que trabalham com a área financeira, na atualidade, com o advento das diversas mudanças impostas pelo sistema capitalista, a preocupação com a educação financeira de qualidade se faz necessário a toda pessoa que lida com dinheiro na atualidade.

Xu e Zia (2012) procuram identificar o que vem a ser a educação financeira, na visão dos autores; engloba conceitos de consciência financeira, suas habilidades, tais como calcular juros compostos, e até mesmo uma desenvoltura mais ampla na gestão de dinheiro e planejamento financeiro na sua vida pessoal.

Educação financeira passa a ser uma prática social na medida em que se faz imprescindível às pessoas, a arte de manejar criticamente a compreensão e a transformação das situações há quais estão inseridos [...] Nesse sentido, o cidadão deve evitar uma postura passiva diante de uma sociedade consumista, com um mercado constituído de informações financeiras e econômicas, cada vez mais complexas (CAMPOS, 2013). Essas circunstâncias em muitos casos levam as pessoas a se endividarem por não possuírem um conhecimento prévio sobre o assunto, em alguns casos a população até conseguem manter algum investimento, mas não sabem nem como funcionam.

Para Lusardi (2008), realizar investimentos, a exemplo, poupanças, os requisitos são bastante exigentes, os indivíduos necessitam obter informações, realizar previsões sobre diversas variáveis, da Seguridade Social, taxas de juros, inflação. E ainda devem fazer os cálculos, e para isso deve ter entendimento de juros compostos. Nesse sentido, estudos no Brasil que venham a evidenciar a importância da educação financeira no processo de tomada de decisões de jovens poderão trazer mais eficiência e eficácia nas finanças pessoais de toda população nessa faixa etária, pois estabelecer uma relação saudável com o dinheiro desde cedo facilita na aptidão de um futuro com independência financeira, e com isso obtenção de uma melhor qualidade de vida.

É o caso de Campos (2013), que em suas pesquisas investiga como a Educação Financeira pode contribuir para decisões de consumo e investimentos de jovens-indivíduosconsumidores, enquanto que, Kistemann Jr. (2012), analisa como as pessoas se comportam e tomam decisões, além de verificar como fazem uso da matemática, ao se depararem com situações de consumo. Complementarmente, Lucci, et al (2006) busca conhecer a situação financeira não só do pesquisado, como também de sua família, além do nível de educação de seus pais, pois para os autores o mapeamento do perfil desses pode ajudar na explicação sobre as atitudes e também sobre o próprio nível de educação financeira dos indivíduos que foram pesquisados.

Exposto essa ideia, surge a seguinte questão de pesquisa: Qual o nível de Educação Financeira dos estudantes das instituições de ensino superior da grande João Pessoa dos cursos Ciências Contábeis no que diz respeito ao comportamento quanto às decisões de consumo e investimento?

O objetivo é identificar o nível de Educação Financeira dos estudantes de Ciências Contábeis em cinco IES de João Pessoa/PB, sendo quatro privadas (A, B, C e D) e uma pública (E) no que diz respeito ao comportamento quanto às decisões de consumo e investimento.

\section{REFERENCIAL TEÓRICO}

\subsection{Educação Financeira no Brasil}

Devido a estabilização e abertura econômica no Brasil, ocorreu uma modernização no mercado financeiro, ao passo que os indivíduos passaram a sentir o quanto é importante o 
conhecimento eficiente e eficaz das finanças, vislumbrando uma tomada de decisão com mais segurança (PEREIRA et al, 2009).

O decreto $n^{\circ} 7.397$, de 22 de dezembro de 2010, que institui a Estratégia Nacional de Educação Financeira (ENEF), tem relevância em promover a Educação Financeira e Previdenciária, fortalecendo a cidadania e o sistema financeiro nacional, além disso, tem como finalidade a tomada de decisões conscientes dos consumidores. Nesse contexto tal decreto relata que a ENEF em seu art. $2^{\circ}$ será executada em conformidade com tais diretrizes:

I - atuação permanente e em âmbito nacional; II - gratuidade das ações de educação financeira; III - prevalência do interesse público; IV - atuação por meio de informação, formação e orientação; V - centralização da gestão e descentralização da execução das atividades; VI - formação de parcerias com órgãos e entidades públicas e instituições privadas; e VII - avaliação e revisão periódicas e permanentes. ENEF (2010)

Silva (2011) afirma que a ENEF institui o desenvolvimento da educação financeira, afetando as decisões de consumo e investimento, resultando num nível maior de qualidade de vida, porém, ainda não se tem clareza sobre como promover de forma eficaz a educação financeira.

Apesar disso, com a deliberação $\mathrm{n}^{\circ} 11$, de 19 de fevereiro de 2013, foram aprovadas orientações objetivando a Educação Financeira de adultos, em que no seu art. $1^{\circ}$ é apresentado um modelo conceitual para construção dos planos, programas e ações de Educação Financeira e Previdenciária nos setores financeiros, de capitais, de seguros, de previdência e de capitalização, de caráter transversal e multidisciplinar.

\subsection{Educação Financeira na Sociedade Capitalista de Consumo}

Kutucuoglu, et al (2013) relata que, a princípio, o conceito de consumo foi apresentado à sociedade de maneira natural e simples. No entanto, no decorrer dos tempos deixou de ser apenas enfatizada para a satisfação das necessidades, ganhando uma estrutura que define o status social, passando a ser um fenômeno social mais complexo, no qual as pessoas consomem bens ou serviços, por razões além de seu valor de uso básico.

Enquanto que, Mandell (2008), em pesquisa realizada na Universidade de Washington e do Instituto Aspen, retrata a preocupação com pessoas que possuem menos renda e Educação Financeira, pois de acordo com tal autor, esses não adquiriram a capacidade de gastar o que tem de maneira mais eficiente, na medida em que, a alfabetização financeira tem de forma explicita implicações macroeconômicas.

Em pleno século XXI, é preciso ter consciência da importância em discutir Educação Financeira, bem como seus significados no que tange às ideias que giram em torno do consumo, planejamento financeiro, e das decisões coerentes que devem ser praticados pelos indivíduos consumidores ao adquirir determinados produtos ou serviços para que não sejam iludidos pelo mercado, além de exercitar o hábito de manejar os objetos matemáticos de cunho financeiroeconômicos, sendo esses imprescindíveis (KISTEMANN JR. 2012).

Um passo importante em destaque no Brasil é a Lei 8.078/90 capítulo III, art. 6, que determina os direitos básicos do consumidor, entre eles;

- A proteção da vida, saúde e segurança contra os riscos provocados por práticas no fornecimento de produtos e serviços considerados perigosos ou nocivos;

- A educação e divulgação sobre o consumo adequado dos produtos e serviços, asseguradas à liberdade de escolha e a igualdade nas contratações;

- A informação adequada e clara sobre os diferentes produtos e serviços, com especificação correta de quantidade, características, composição, qualidade, tributos incidentes e preço, bem como sobre os riscos que apresentem;

R. Cont. Ufba, Salvador-Ba, v. 9, n. 3, p. 103 - 117, set-dez 2015 
- A proteção contra a publicidade enganosa e abusiva, métodos comerciais coercitivos ou desleais, bem como contra práticas e cláusulas abusivas ou impostas no fornecimento de produtos e serviços.

Apesar disso é verificada a alienação do consumidor provocada pelo sistema capitalista de Marketing, na qual gera falsas necessidades a produtos, por meio de propagandas e comerciais de empresas preocupadas apenas com seus interesses. Ao passo que no site do Banco Central do Brasil, em seu programa de Educação Financeira, são relatados que diversos é os produtos oferecidos aos consumidores de serviços financeiros, o que também decorre em uma evidente responsabilidade nas opções de escolhas a serem tomadas.

Ainda, de acordo com o relatório para a Estabilidade Financeira do mês de Setembro de 2013, do Banco Central do Brasil, apesar do comprometimento de renda das famílias terem apresentado uma redução expressiva no último ano, alcançando $21,5 \%$ em junho de 2013 , ante $23,0 \%$ doze meses antes, o endividamento doméstico manteve-se elevada, apesar de que em ritmo mais moderado, atingindo 44,8\% em junho de 2013. Elevação essa explicada em grande parte, pelo crescimento do financiamento imobiliário.

Vale salientar que, para Kistemann Jr. (2011), a família, é a primeira e mais importante meio para se efetuar a educação financeira de uma pessoa, mas a escola deve se responsabilizar também por essa educação, propiciando a gênese do pensamento financeiro-econômico no indivíduo-consumidor.

Contudo, no Canadá, pelo Credit Canadá/Capital One, em 2008, foi realizada uma análise que teve como implicação o fato de muitos pais confirmarem não ter desenvoltura com o dinheiro, e que estão transmitindo seus maus hábitos aos filhos, e ainda, 52\% dos pais acreditam que quando eram jovens não se sentiam preparados gerir seus recursos (INTERNATIONAL GATEWAY FOR FINANCIAL EDUCATION - IGEF, 2010).

\subsection{A Importância De Investimento Em Educação Financeira}

Segundo Mandell (2009), em seu estudo, foi constatado na amostra que graduações em economia, contabilidade e finanças pessoais não tiveram grandes impactos sobre a alfabetização financeira, e nenhum no que tange ao comportamento financeiro. No entanto, Vieira, et al (2009), verificou como resultados de sua pesquisa que, a formação acadêmica dos estudantes participantes do estudo, contribui para uma melhor tomada de decisão, tanto no consumo, como em investimento e poupança, mesmo não sendo analisadas experiências práticas e a família dos indivíduos.

A formação acadêmica em áreas afins a finanças, influenciando ou não na tomada de decisões quanto ao consumo e investimentos, não tira a credibilidade da Educação Financeira. Behrman (2010) aponta que, o impacto de uma alfabetização financeira é economicamente viável, e por sua vez, investimentos nessa área podem muito bem trazer grandes retornos.

E ainda, Jappelli e Padula (2011) argumentam em suas análises que há uma ligação entre a educação financeira e o acúmulo de riquezas, dessa maneira, reformas dos mercados financeiros associados, a exemplo, as criações de fundos de pensões privadas podem aumentar o incentivo para investir na alfabetização financeira, bem como na poupança.

Segundo Jappelli e Padula (2011), países com mais alfabetização financeira têm taxas de poupança maiores. Dessa forma sugerem que, havendo uma melhoria nas competências matemáticas pode ocorrer o avanço da educação financeira de uma nação, e por sua vez a acumulação de recursos.

Para Miranda e Costa (2012), a teoria do capital humano, procura enfatizar os ganhos de produtividade a partir do grau de instrução, afirmando que as pessoas mais escolarizadas se 
tornam mais produtivas e mais aptas a desempenhar novas atividades e a enfrentar ambientes em mudança com mais ágil.

Nesse sentido, a educação financeira é vista como um capital humano, ao passo que com capacidade numérica e conhecimento avançado, é indispensável ao indivíduo nas decisões financeiras. Ainda, para atingir a alfabetização financeira é preciso tanto a percepção do benefício de gastar tempo e esforço em aquisição de livros da área, cursos, conversas entre amigos, ou à procura on-line para coletar informações, bem como a educação financeira familiar (FINKE; HOWE; HUSTON, 2011).

Ainda como sustentação teórica, tem-se a Figura 01, a seguir, que representa o Modelo do Ciclo de Vida abordado na pesquisa de Oreiro (2003):

Figura 01: Teoria do Ciclo de Vida

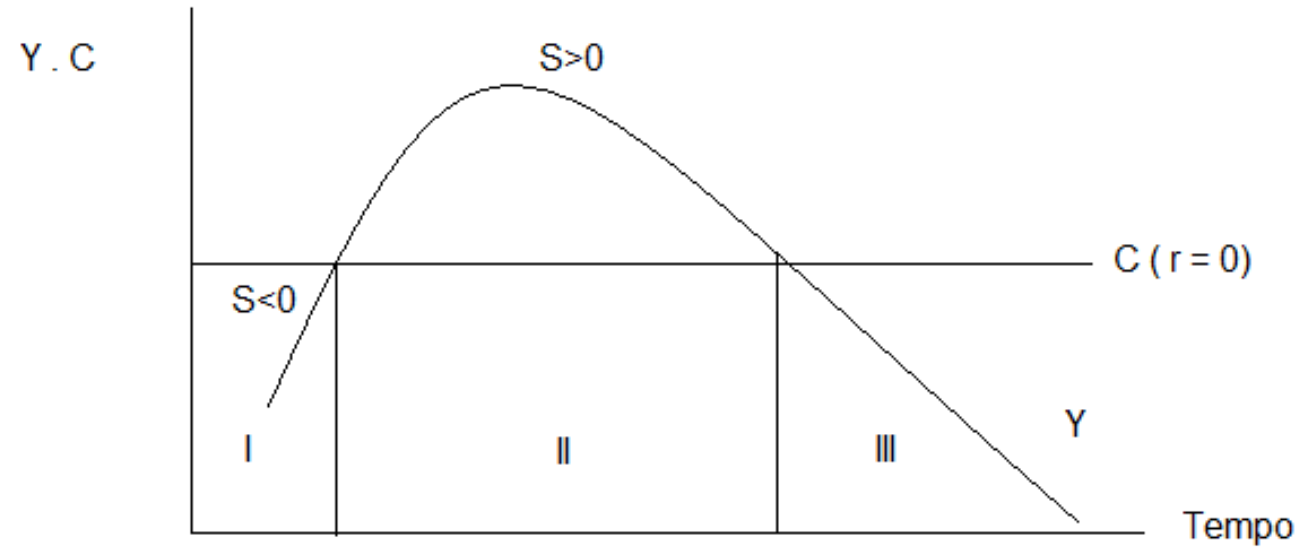

Fonte: Oreiro (2003)

Com relação a Figura 01, é possível verificar que no Estágio I os jovens tendem a poupar menos, vislumbrando uma melhor renda no futuro, já no Estágio II, durante a meia idade, os indivíduos passam a pagar a dívida e poupar para a aposentadoria, enquanto que, no Estágio III, na aposentadoria, apesar da renda tendem a serem zero, as pessoas passam a satisfazer sua necessidade de consumo, e poupar menos.

\subsection{Construção das Hipóteses}

O estudo foi estruturado por meio de um conjunto de três hipóteses, para as quais as verificações são possíveis a partir das análises estatísticas dos dados. A primeira é relacionada as situações de endividamento dos entrevistados à educação financeira. Na qual, Savoi, Saito e Santana (2007), afirmam que o alto nível de envidividamento é fruto de uma sociedade que incentiva o consumo cada vez mais, por meio de publicidades diversas, na mídia e no marketing, influenciando a tomada de decisão dos indivíduos, que sem educação financeira, podem vir a comprar por que a parcela cabe no orçamento, porém sem saberem que estão pagando o dobro do preço do bem ou serviço adquirido. Os autores ainda relatam o papel do governo que através da disponibilização de crédito, movimenta os mercados para aumentar a produção das firmas. Nesse aspecto, segue a primeira hipótese:

$\mathbf{H}_{1}$ : Os alunos que não estão em situação de alto índice de endividamento possuem melhor educação financeira; 
Ainda, quanto a segunda hipótese, levando em consideração o Modelo de Ciclo de Vida, idealizado por Modigliani e Brumberg (1954), na qual determina que tanto a poupança, quanto o consumo não estão sujeitos apenas a renda corrente, mas também a uma expectativa de vida para o futuro, Miranda e Costa (2012) argumentam que essa teoria considera que os indivíduos tomam decisões observando a opção de consumir no presente ou poupar para o futuro, na qual, os jovens tendem a poupar menos. Com isso, presume-se que:

$\mathbf{H}_{2}$ : Os alunos preferem os riscos em detrimento a estabilidade nos retornos dos investimentos;

Por último, a terceira hipótese sugere que há uma relação positiva entre o nível escolaridade dos pais dos entrevistados em relação à educação financeira. A medida que, de acordo com Lucci, et al (2006) e Lucena e Marinho (2013), a educação financeira é formada a partir da ação dos pais junto à escola, onde a formação escolar e os conhecimentos dos pais quanto às finanças é bastante importante para transmitir aos filhos os saberes necessários sobre as melhores decisões de consumo e investimentos. Por isso, conjetura-se a última hipótese de pesquisa deste estudo:

$\mathbf{H}_{3}$ : Os alunos que possuem pais com maior nível de escolaridade tem uma melhor educação financeira.

\section{METODOLOGIA}

No que se refere à Tipologia de pesquisa, no que tange aos objetivos, optou-se pela exploratória, em que de acordo o pensamento de Raupp; Beuren (2006), a pesquisa exploratória é utilizada quando não há muitos estudos sobre o tema abordado.

Quanto aos procedimentos, foi realizada uma pesquisa bibliográfica, além do Levantamento ou Survey, em que para Gil (1999) se caracteriza pela interrogação direta das pessoas cujo comportamento se deseja conhecerem, em que são solicitadas informações a um determinado grupo de pessoas acerca de um problema, mediante análise quantitativa, obtendo com isso conclusões aos dados que vierem a ser coletados. Para satisfazer as necessidades da pesquisa, quanto à abordagem do problema, assume uma característica quantitativa, que se caracteriza um emprego de instrumentos estatísticos, tanto na coleta quanto no tratamento dos dados.

As informações foram tratadas com a utilização do programa estatístico SPSS versão XX, com o intuito de tabular os dados, na medida em que, foram coletados levando-se em consideração as turmas reconhecidas pelo Exame Nacional de Desempenho de Estudantes (Enade), que é integrado ao Sistema Nacional de Avaliação de Educação Superior (Sinaes), na qual é avaliado o rendimento de estudantes de graduação.

Foram selecionadas quatro instituições particulares (A, B, C e D) e uma pública (E). Como procedimento metodológico, foi utilizado o Questionário, em que Marconi e Lakatos (2007, p.203) relatam ser "Um instrumento de coleta de dados, constituído por uma série ordenada de perguntas, que devem ser respondidas por escrito [...]". Vale lembrar que os quesitos foram baseados no questionário de Lucci, et al (2006).

O questionário foi aplicado a uma amostra de 264 discentes, entre iniciantes e concluintes do curso de Ciências Contábeis, durante o mês de setembro de 2013, sendo utilizado o método funil, que segundo Gil (1999), cada quesito é relacionado ao quesito anterior, além disso, são expostas as questões mais amplas, às mais específicas, respectivamente. Vale salientar que a pesquisa é não probabilística, e que a quantidade de entrevistados não corresponde ao total de 
estudantes matriculados nos cursos. Pelo fato de na data da aplicação do questionário alguns alunos não se encontravam ou se recusaram a responder.

\section{APRESENTAÇÃO DOS RESULTADOS}

No primeiro momento as questões dão ênfase às características socioeconômica dos entrevistados, em seguida, é verificado o grau de Educação Financeira dos participantes no que diz respeito ao comportamento quanto às decisões de consumo e investimento.

\subsection{Características Socioeconômicas dos Entrevistados}

Tabela 01: Correlação entre gênero e período do curso

\begin{tabular}{c|c|c|c}
\hline \multirow{2}{*}{ Gênero } & \multicolumn{2}{|c|}{ Período do curso } & \multirow{2}{*}{ Total } \\
\cline { 2 - 3 } & Iniciante & Concluinte & \\
\hline Masculino & 108 & 18 & 126 \\
\hline Feminino & 100 & 38 & 138 \\
\hline Total & 208 & 56 & 264 \\
\hline
\end{tabular}

Fonte: Dados da pesquisa

De acordo com a tabela 01, destaca-se que dos 264 participantes da pesquisa, 78,78\% são iniciantes no curso de Contabilidade enquanto que, $21,22 \%$ representam os concluintes. E do total de 208 iniciantes, $52 \%$ são do gênero masculino, e 48\%, do gênero feminino, evidenciando que a procura por essa área esta equilibrada no que tange ao gênero. Contudo, é notório que dos 56 estudantes concluintes da graduação, $67,86 \%$ são mulheres.

Tabela 02: Correlação entre IES e período do curso

\begin{tabular}{c|c|c|c}
\hline \multirow{2}{*}{$\begin{array}{c}\text { IES onde cursa Ciências } \\
\text { Contábeis }\end{array}$} & \multicolumn{2}{|c|}{ Qual o período do curso } & \multirow{2}{*}{ Total } \\
\cline { 2 - 3 } & Iniciante & Concluinte & \\
\hline Pública & 58 & 15 & 73 \\
\hline Privada & 150 & 41 & 191 \\
\hline Total & 208 & 56 & 264 \\
\hline
\end{tabular}

Fonte: Dados da pesquisa

Com a tabela 02, fica evidente que quanto ao período do curso, deve-se atentar pelo fato de que dos 208 iniciantes, 72,11\% são de instituições de ensino privadas. Na medida em que, do total de entrevistados, $72,35 \%$ dos estudantes cursam Ciências Contábeis em instituição de ensino particular, o que remete a fatores determinantes, como o fato de que apesar da IES pública disponibilizar vagas para dois turnos, totalizando 100 vagas por semestre, o número de vagas das IES privadas são 4 vezes maior, nesse sentido, os que não conseguem passar no processo seletivo da universidade pública, recorrem a uma instituição particular.

Tabela 03: Correlação entre IES e escolaridade do pai

\begin{tabular}{|c|c|c|c|c|c|c|c|c|}
\hline \multirow{2}{*}{$\begin{array}{l}\text { IES onde } \\
\text { cursa } \\
\text { Ciências } \\
\text { Contábeis }\end{array}$} & \multicolumn{7}{|c|}{ Escolaridade do pai } & \multirow[b]{2}{*}{ Total } \\
\hline & $\begin{array}{c}\text { Ensino } \\
\text { fundamental } \\
1^{\circ} \mathrm{a} 4^{\circ} \\
\end{array}$ & $\begin{array}{c}\text { Ensino } \\
\text { fundamental } \\
5^{\circ} \text { ao } 9^{\circ} \\
\end{array}$ & $\begin{array}{c}\begin{array}{c}\text { Ensino } \\
\text { médio } \\
\text { incompleto }\end{array} \\
\end{array}$ & $\begin{array}{c}\text { Ensino } \\
\text { médio } \\
\text { completo }\end{array}$ & $\begin{array}{c}\text { Ensino } \\
\text { superior } \\
\text { incompleto } \\
\end{array}$ & $\begin{array}{c}\text { Ensino } \\
\text { superior } \\
\text { completo } \\
\end{array}$ & $\begin{array}{c}\text { Sem } \\
\text { escolaridade }\end{array}$ & \\
\hline Pública & 12 & 15 & 6 & 25 & 4 & 10 & 1 & 73 \\
\hline
\end{tabular}

R. Cont. Ufba, Salvador-Ba, v. 9, n. 3, p. 103 - 117, set-dez 2015 


\begin{tabular}{c|c|c|c|c|c|c|l|l} 
Privada & 26 & 30 & 24 & 62 & 13 & 28 & 8 & 191 \\
\hline Total & 38 & 45 & 30 & 87 & 17 & 38 & 9 & 264 \\
\hline
\end{tabular}

Fonte: Dados da pesquisa

Com as informações disponibilizadas na Tabela 03, do total de 87 respostas, $71,27 \%$ dos alunos de IES privada, afirmaram que seus pais possuem o ensino médio completo, enquanto que, $28,73 \%$ dos de IES pública também afirmaram que seus pais têm esse mesmo grau de ensino, sendo esses percentuais os mais elevados.

Tabela 04: Correlação entre IES e escolaridade da mãe

\begin{tabular}{c|c|c|c|c|c|c|c|c}
\hline \multirow{2}{*}{$\begin{array}{c}\text { IES onde cursa } \\
\text { ciências } \\
\text { Contábeis }\end{array}$} & \begin{tabular}{c} 
Ensino \\
\cline { 2 - 9 } \\
fundamental \\
$\mathbf{1}^{\mathbf{0}} \mathbf{4}^{\mathbf{0}}$
\end{tabular} & $\begin{array}{c}\text { Ensino } \\
\text { fundamental } \\
\mathbf{5}^{\mathbf{0}} \mathbf{a 0} \mathbf{9}^{\mathbf{0}}\end{array}$ & $\begin{array}{c}\text { Ensino } \\
\text { médio } \\
\text { incompleto }\end{array}$ & $\begin{array}{c}\text { Ensino } \\
\text { médio } \\
\text { completo }\end{array}$ & $\begin{array}{c}\text { Ensino } \\
\text { superior } \\
\text { incompleto }\end{array}$ & $\begin{array}{c}\text { Ensino } \\
\text { superior } \\
\text { completo }\end{array}$ & $\begin{array}{c}\text { Sem } \\
\text { escolaridade }\end{array}$ & Total \\
\hline Pública & 11 & 9 & 9 & 20 & 5 & 19 & 0 & 73 \\
\hline Privada & 17 & 40 & 16 & 54 & 21 & 38 & 5 & 191 \\
\hline Total & 28 & 49 & 25 & 74 & 26 & 57 & 5 & 264 \\
\hline
\end{tabular}

Fonte: Dados da pesquisa

Analisando a Tabela 04, os percentuais mais evidentes se referem ao nível de escolaridade do ensino médio completo, assim como na tabela anterior, em que do total de 74 respostas, 72,97\% se referem às mães de alunos das escolas particulares, 27,03\%, da pública. Contudo, considerando as tabelas 3 e 4, respectivamente, das 264 quesitos, 14,40\% dos pais possuem o ensino superior completo, já $21,60 \%$ das mães possuem esse mesmo grau de instrução.

\subsection{Nível de Educação Financeira dos Respondentes Quanto ao Comportamento nas Decisões de Consumo e Investimento}

Tabela 05: Correlação entre gênero e percepção dos entrevistados quando aos conhecimentos para gerenciar seus recursos.

\begin{tabular}{|c|c|c|c|c|c|c|}
\hline \multirow{2}{*}{ Gênero } & \multicolumn{5}{|c|}{$\begin{array}{l}\text { Como você se sente a respeito dos seus conhecimentos para gerenciar } \\
\text { seu próprio dinheiro }\end{array}$} & \multirow{2}{*}{ Total } \\
\hline & $\begin{array}{c}\text { Nada } \\
\text { seguro } \\
\end{array}$ & $\begin{array}{l}\text { Não muito } \\
\text { seguro }\end{array}$ & $\begin{array}{c}\text { Razoavelmente } \\
\text { seguro }\end{array}$ & Seguro & $\begin{array}{l}\text { Muito } \\
\text { seguro }\end{array}$ & \\
\hline Masculino & 9 & 18 & 52 & 40 & 7 & 126 \\
\hline Feminino & 11 & 22 & 66 & 32 & 7 & 138 \\
\hline Total & 20 & 40 & 118 & 72 & 14 & 264 \\
\hline
\end{tabular}

Fonte: Dados da pesquisa

O resultado obtido confirma que $41,27 \%$ do total de 126 do gênero masculino, e 47,83\% do total de 138 do gênero feminino, acreditam estarem apenas razoavelmente seguros quanto à administração do dinheiro. É nesse momento que é observado a educação financeira como um instrumento indispensável nas decisões de consumo e investimento, pois este que gera renda e empregos às famílias, sendo bem gerenciado e consciente será um grande subsídio aos indivíduos. Devem ser ressaltados os quatro aspectos que giram em torno das decisões dos indivíduos no que diz respeito à educação financeira; a escola, a família, as instituições financeira/comércio e produtos financeiros disponíveis no mercado (CAMPOS, 2013). 
Tabela 06: Correlação entre IES e opções de investimento

\begin{tabular}{c|c|c|c|c|c}
\hline \multirow{2}{*}{$\begin{array}{c}\text { IES onde cursa } \\
\text { Ciências Contábeis }\end{array}$} & \multicolumn{3}{|c|}{$\begin{array}{c}\text { Se tivesse recursos para investir, sem prazo definido, para } \\
\text { resgatar, com qual das alternativas abaixo você mais se } \\
\text { identificaria como aplicador. }\end{array}$} & \multirow{2}{*}{ Total } \\
\cline { 2 - 6 } & Ações & $\begin{array}{c}\text { Fundos de } \\
\text { Investimentos }\end{array}$ & Poupança & Bens & \\
\hline Pública & 7 & 13 & 23 & 30 & 73 \\
\hline Privada & 22 & 22 & 76 & 71 & 191 \\
\hline Total & 29 & 35 & 99 & 101 & 264 \\
\hline
\end{tabular}

Fonte: Dados da pesquisa

É interessante observar que entre as opções de investimentos, os jovens tanto de instituições particulares quanto da pública optaram pelos bens $(38,25 \%)$ e poupança $(37,5 \%)$, respectivamente. Ou seja, sendo preferida a estabilidade do investimento, e evitado os riscos de retorno perante ações e fundos de investimentos.

Tabela 07: $1^{\circ}$ Teste Mann Whitney U e Significância

\begin{tabular}{|c|c|c|c|c|c|c|}
\hline & Gênero & $\begin{array}{c}\text { Fonte } \\
\text { principal } \\
\text { de renda }\end{array}$ & $\begin{array}{c}\text { Faixa de } \\
\text { renda } \\
\text { mensal } \\
\text { líquida } \\
\text { pessoal }\end{array}$ & $\begin{array}{c}\text { Faixa de } \\
\text { renda } \\
\text { mensal } \\
\text { líquida } \\
\text { familiar }\end{array}$ & $\begin{array}{l}\text { Como se sente a } \\
\text { respeito dos seus } \\
\text { conhecimentos } \\
\text { para gerenciar } \\
\text { seu próprio } \\
\text { dinheiro }\end{array}$ & $\begin{array}{c}\text { Dirceu e Roberto têm o } \\
\text { mesmo salário. Ambos } \\
\text { desejam comprar um } \\
\text { carro no valor de } R \$ \\
10.000,00 \text {. Quem pagou } \\
\text { mais pelo bem? }\end{array}$ \\
\hline $\begin{array}{c}\text { Mann- } \\
\text { Whitney U }\end{array}$ & 4672 & 4521 & 4013,5 & 3224,5 & 4317 & 4600 \\
\hline Wilcoxon W & 26408 & 6117 & 25749,5 & 24960,5 & 26053 & 26336 \\
\hline $\mathrm{Z}$ & $-2,625$ & $-2,947$ & $-3,727$ & $-5,222$ & $-3,156$ & $-2,917$ \\
\hline $\begin{array}{c}\text { Asymp. Sig. } \\
\text { (2-tailed) }\end{array}$ & 0,009 & 0,003 & 0,000 & 0,000 & 0,002 & 0,004 \\
\hline
\end{tabular}

a. Grouping Variable: Período do curso. Fonte: Dados da pesquisa

Foram encontradas diferenças significativas entre a variável, período do curso e gênero, em 0,009. Além do período do curso e fonte principal de renda, em 0,003, pois dos 264 entrevistados, 60,61\% responderam possuir emprego formal, e que desses 160 estudantes, $75,50 \%$ são iniciantes no curso, na medida em que das cinco instituições, em três delas, o curso de Ciências Contábeis funciona apenas a noite, o que é bastante favorável aos que trabalham durante o dia.

Quanto à renda mensal líquida pessoal, 38,64\%, dos 264 respondentes, afirmaram receber até um salário mínimo. Sendo que do total de novatos no curso, 43,75\% também recebem esse mesmo valor. Vale lembrar que nesse período os alunos estão apenas começando à graduação, bem como podem estar iniciando a vida profissional, por se tratar de jovens estudantes. Enquanto que do total de concluintes, em uma porcentagem de $19,64 \%$, sendo essa a mais relevante, afirmaram receber entre $\mathrm{R} \$ 678,00$ à $\mathrm{R} \$ 1.000,00$.

Outra característica interessante é quanto à renda mensal líquida familiar, e sua relação com o período do curso, pois dos 264 estudantes participantes da pesquisa, 23,86\% optaram pela alternativa de faixa salarial entre $\mathrm{R} \$ 1.500,01$ até $\mathrm{R} \$ 2.500,00$, na medida em que dos 208 iniciantes, 23,19\% também optaram por essa resposta. Já a porcentagem mais significativa do total de alunos que estão concluindo o curso é de $37,50 \%$, que por sua vez optaram por responder à faixa de salário familiar entre $\mathrm{R} \$ 2.500,00$ até $\mathrm{R} \$ 4.000,00$. 
O nível de significância entre a variável, período do curso e sentimento quanto aos conhecimentos para gerir os recursos é de 0,002 , tendo em vista que do total de entrevistados, $44,70 \%$ afirmaram ser razoavelmente seguros, e desse percentual, 76,27\% são iniciantes. Vale destacar que apenas 5,30\% dos 264 alunos se sentem muito seguros para administrar seu dinheiro.

Na situação hipotética em que é questionado quem pagou mais por comprar um carro no valor de $\mathrm{R} \$ 10.000,00$, dos 264 entrevistados, 64,77\% disseram ser Dirceu, que comprou hoje, financiando o saldo devedor por 24 meses, e 35,23\% afirmaram ser Roberto, que preferiu poupar por 15 meses, mas comprou o carro à vista. Ou seja, mais de $50 \%$ dos estudantes acreditam que realizar um financiamento é menos proveitoso a poupar dinheiro para comprar a vista no momento oportuno. Além disso, dos 208 iniciantes, 69,23\% optaram pela primeira alternativa, contudo, dos 56 concluintes, $51,78 \%$ afirmaram ser Roberto quem saiu em desvantagem no negócio.

Tabela 08: $2^{\circ}$ Teste Mann Whitney U e Significância

\begin{tabular}{c|c|c|c|c}
\hline & $\begin{array}{c}\text { Escolaridade } \\
\text { da Mãe }\end{array}$ & $\begin{array}{c}\text { Qual sua } \\
\text { faixa de } \\
\text { renda mensal } \\
\text { líquida } \\
\text { pessoal }\end{array}$ & $\begin{array}{c}\text { Ao fazer compras, } \\
\text { você se preocupa com } \\
\text { a qualidade e preço } \\
\text { dos produtos? }\end{array}$ & $\begin{array}{c}\text { Dirceu e Roberto têm o mesmo } \\
\text { salário. Ambos desejam comprar } \\
\text { um carro no valor de R\$ } \\
\text { 10.000,00. Quem pagou mais pelo } \\
\text { bem }\end{array}$ \\
\hline Mann-Whitney U & 613 & 497,5 & 609 & 653,5 \\
\hline Wilcoxon W & 749 & 6492,5 & 6604 & 6648,5 \\
\hline Z & $-1,972$ & $-3,042$ & $-2,441$ & $-1,962$ \\
\hline $\begin{array}{c}\text { Asymp. Sig. (2- } \\
\text { tailed) }\end{array}$ & 0,049 & 0,002 & 0,015 & 0,05 \\
\hline
\end{tabular}

a. Grouping Variable: Você tem algum tipo de dívida (empréstimo, financiamentos, rotativo do cartão)

Fonte: Dados da pesquisa

Com os testes da Tabela 08, há um nível de significância evidente entre a escolaridade da mãe e as dívidas que os estudantes necessitam quitar, em 0,049. Ao passo que, dos 264 questionários aplicados, 41,29\% disseram que não tem dívidas pessoais, sempre realizam o planejamento necessário para comprar à vista e com desconto, na medida em que do total desse percentual, 32,11\% das mães possuem o ensino superior completo, sendo tais dados os mais relevantes. Vale ressaltar que dos 109 entrevistados que optaram por responder não ter dívida pessoal, 61,47\% afirmaram possui uma renda mensal líquida pessoal de até $\mathrm{R} \$ 678,00$.

Outra peculiaridade é que dos 109 estudantes que afirmaram não estar endividados, $74,31 \%$ sempre se preocupam com a qualidade e preços dos produtos, sendo representado pelo nível de significância 0,015. Além disso, no que tange a situação hipotética de Dirceu e Roberto, já explicado anteriormente, dos 64,77\% que disseram que Dirceu pagou mais dinheiro ao fazer o financiamento do veículo, em detrimento de efetuar a poupança e adquirir o bem depois, 43,86\% não tem algum tipo de dívida pessoal.

\section{CONSIDERAÇÕES FINAIS}

Conclui-se que quanto ao nível de educação financeira dos entrevistados é possível notar o fato de que apenas 5,30\% do total de entrevistados se sentem muito seguros nas decisões de administrar os seus recursos, e 44,70\% estarem razoavelmente seguros. Apesar disso, àqueles que afirmaram não estar em situação de endividamento demonstram possuir uma maior educação nas finanças pessoais, pois $74,31 \%$ desses observam a qualidade e preços dos produtos que adquirem, bem como ter tido uma percentagem evidente daqueles que acreditam que ter uma 
poupança para adquirir algo que deseja, posteriormente, é melhor, há optar por financiamentos. Ou seja, os alunos que não estão em situação de alto índice de endividamento possuem melhor educação financeira ( $1^{\mathrm{a}}$ hipótese).

Quanto a $2^{\text {a }}$ hipótese, só é afirmada em relação aos 56 alunos concluintes do curso de Contabilidade, no quesito que envolve a opção entre poupar para adquirir depois ou financiar, (confirmando a Teoria do Ciclo de Vida) pois $51,78 \%$ responderam o financiamento como melhor opção, vale lembrar que esse último geralmente está acompanhado de juros. No entanto, é verificado que os respondentes de modo geral, ou seja, dos 264 alunos, uma percentagem considerável optaram pela estabilidade nos retornos dos investimentos em detrimento aos riscos, evidenciado pela escolha dos bens $(38,25 \%)$ e poupança $(37,5 \%)$, respectivamente, verificado na tabela 06.

Com relação a $3^{\text {a }}$ hipótese, apesar de os dados referentes aos pais não apresentarem resultados significantes, no que tange às mães com maiores níveis de escolaridades, estas contribuem bastante para uma educação financeira mais adequada dos seus filhos. Respondido pelo teste de Mann-Whitney U, em que há significância entre as mães com nível de instrução superior e seus filhos, entrevistados estes que possuem o hábito de planejar suas compras à vista e com desconto.

Por fim, o tema relacionado à educação financeira é bastante amplo, e rico em informações, dessa maneira é sugerido para pesquisas futuras um número maior de entrevistados, e não apenas os iniciantes e concluintes do curso de Ciências Contábeis, sendo uma limitação do estudo, mas também alunos de Economia e Administração, com o intuito de haver a comparação dos conhecimentos em educação financeira entre estudantes de áreas afins.

\section{REFERÊNCIAS}

BACEN. Relatório de Estabilidade Financeira. Disponível em < http://www.bcb.gov.br/htms/estabilidade/2013_09/refP.pdf> Acesso em: 10 de Novembro de 2013.

BRASIL, Decreto $\mathbf{n}^{\mathbf{0}} \mathbf{7 . 3 9 7}$, de 22 de dezembro de 2010: Disponível em <http://www.planalto.gov.br/ccivil_03/_Ato2007-2010/2010/Decreto/D7397.htm> Acesso em 14 de Julho de 2013.

BRASIL, Deliberação $\mathbf{n}^{0} \mathbf{1 1}$, de 19 de fevereiro de 2013. Disponível em: < http://www.vidaedinheiro.gov.br/legislacao/Arquivo/Deliberacao-n11-ProgEducFinanceiraAdultos.pdf > Acesso em 14 de Julho de 2013.

BRASIL, LEI 8.078/90 - Código de Defesa do Consumidor. Disponível em< http://www.planalto.gov.br/ccivil_03/leis/18078.htm> Acesso em: 10 de Novembro de 2013.

BEHRMAN, Jere R. et al. Behrman. Financial literacy, schooling, and wealth accumulation. National Bureau of Economic Research, Outubro de 2010. Disponível em: < http://www.nber.org/papers/w16452> Acesso em 14 de Julho de 2013.

CAMPOS, André Bernardo. Investigando como a educação financeira crítica pode contribuir para tomada de decisões de consumo de jovens-indivíduos-consumidores (jic's). UFJF, Juiz de Fora (MG), Março de 2013. Disponível em < http://www.ufjf.br/mestradoedumat/files/2011/05/Disserta\%C3\%A7\%C3\%A3o-AndreCampos.pdf> Acesso em 14 de Julho de 2013. 
FINKE, Michael S.; HOWE, John S.; HUSTON, Sandra J. Old Age and the Decline in Financial Literacy. SSRN, August 24, 2011. Disponível em: < http://papers.ssrn.com/sol3/papers.cfm?abstract_id=1948627\%20> Acesso em: 09 de Novembro de 2013.

GIL, Antonio Carlos. Métodos e Técnicas de Pesquisa Social. 5.ed. São Paulo: Atlas, 1999.

INTERNATIONAL GATEWAY FOR FINANCIAL EDUCATION - IGEF, 2010. Disponível: < http://www.financial-education.org/home.html> Acesso em: 03 de Dezembro de 2013.

JAPPELLI, Tullio; PADULA, Mario. Investment in financial literacy and saving decisions. Journal of Banking \& Finance, Julho de 2011. Disponível em: <http://www.sciencedirect.com/science/article/pii/S0378426613001623> Acesso em 14 de Julho de 2013.

KISTEMANN JR, Marco Aurélio. Sobre a produção de significados e a tomada de decisão de indivíduos-consumidores. III EIEMAT, $1^{\circ}$ Encontro Nacional de PIBID-Matemática, 01 a 03 de Agosto de 2012. Disponível em: < http://w3.ufsm.br/ceem/eiemat/Anais/arquivos/CC/CC_Kistemann_Marco.pdf> Acesso em 14 de Julho de 2013.

KUTUCUOGLU, by

Kemaly. Consumption, consumer culture and consumer society.Journal of Community Positive Pra ctices (Jurnalul Practicilor Comunitare Pozitive), issue: 1 / 2013,pages: 182-203, Disponível em:< www.ceeol.com > Acesso em 14 de Julho de 2013.

LUCCI, C. ; ZERRENNER, S.; VERRONE, M.; SANTOS, S. A. A influência da Educação Financeira nas decisões de consumo e investimento dos indivíduos. IX SEMEAD, Administração no contexto internacional. Seminário em Administração FEA-USP, 2006.

LUCENA, W. G. L., MARINHO, R. A. L. Competências financeiras: uma análise das decisões financeiras dos discentes no tocante as finanças pessoais. XVI SEMEAD FEAUSP 2013, São Paulo.

\section{LUSARDI, A. Financial Literacy: An Essential Tool for Informed Consumer Choice?} Working Paper 14084. NBER Working Paper, 2008. Disponível em: <http://www.nber.org/papers/w14084.pdf?new_window=1> Acesso em: 10 de Novembro de 2012.

MANDELL, L. The Financial Literacy Of Young American Adults: Results of the 2008 National Jump\$tart Coalition Survey of High School Seniors and College Students. For the JumpStart Coalition® for Personal Financial Literacy: 2008.

MANDELL, by Lewis Mandell. The Impact of Financial Education in High School and College On Financial Literacy and Subsequent Financial Decision Making. Presented at the American Economic Association Meetings, San Francisco, CA, Janeiro de 2009. Disponível em:

<http://www.americasaves.org/elements/www.americasaves.org/file/Fin\%20Behavior\%20and $\% 20 \mathrm{Ed} \% 20 \mathrm{v} 2$.pdf $>$ acesso em 14 de julho de 2013. 
MARCONI, Maria de Andrade; LAKATOS, Eva Maria. Técnicas de pesquisa. In:

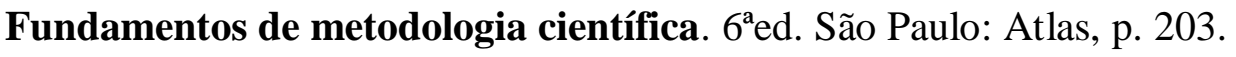

MIRANDA, Cleber José de; COSTA, Cristiano M. Educação financeira e a determinação da taxa de poupança. ANPCONT, 2012. Disponível em: <http://www.furb.br/_upl/files/especiais/anpcont\%207/3806/mfc\%20241.pdf?201310310559 55> Acesso em: 10 de Novembro de 2013.

MODIGLIANI, F.; BRUMBERG, Richard H. Utility analysis and the consumption function:an interpretation of cross-section data, In: Kenneth K. Kurihara, (ed.) PostKeynesian Economics, New Brunswick, NJ. Rutgers University Press, 1954.

OREIRO, F. D. R. Os microfundamentos do consumo: de Keynes até a versão moderna da teoria da renda permanente. Revista de Economia SER, UFPR, 2003. Disponível em: < http://ojs.c3sl.ufpr.br/ojs2/index.php/economia/article/viewArticle/1996> Acesso em: 10 de Novembro de 2013.

PEREIRA, Hilário Débora, et al. Educação financeira infantil seu impacto no consumo consciente. São 2009 Paulo, Disponível em http://www.educacaofinanceira.com.br/tcc/impactoconsumoconsciente.pdf $>>$ Acesso em 14 de Julho de 2013.

RAUPP, Fabiano Maury; BEUREN, Ilse Maria. Metodologia da Pesquisa Aplicável às Ciências Sociais. In: LONGARAY, André Andrade. et all. Como elaborar trabalhos monográficos em Contabilidade: Teoria e Prática. 3 ed. São Paulo: Atlas, 2006.

SAVOIA, J, R. F.; SAITO, A. T.; SANTANA, F. A. Paradigmas da educação financeira no Brasil, RAP, Rio de Janeiro, Nov e Dez, 2007.

SILVA, Bruna Soares da. Educação financeira e tomada de decisão: Um estudo aplicado a acadêmicos da fecilcam. VI EPCT, 24 a 28 de Outubro de 2011. Disponível em: http://www.fecilcam.br/nupem/anais_vi_epct/PDF/ciencias_sociais/15.pdf. Acesso em 14 de Julho de 2013.

VIEIRA, Saulo Fabiano Amâncio, et al. Educação financeira e decisões de consumo, investimento e poupança: Uma análise dos alunos de uma universidade pública do Paraná, SEMEAD, 2009. Disponível em: <http://www.ead.fea.usp.br/semead/12semead/resultado/trabalhosPDF/341.pdf> Acesso em 14 de Julho de 2013.

XU, Lisa; ZIA, Bilal. Financial Literacy around the World: An Overview of the Evidence with Practical Suggestions for the Way Forward. World Bank Policy Research Working Paper, SSRN, Junho de 2012. Disponível em http://papers.ssrn.com/sol3/papers.cfm?abstract_id=2094887> Acesso em 14 de Julho de 2013 


\section{ANEXO \\ A educação financeira como um diferencial nas decisões de consumo e investimento dos estudantes do curso de Ciências Contábeis na grande João Pessoa.}

\begin{tabular}{|c|c|}
\hline $\mathbf{1}^{\circ}$ Nível de escolaridade do seu pai: & $\mathbf{2}^{\mathbf{0}}$ Nível de escolaridade da sua mãe: \\
\hline ( ) Ensino Fundamental de $1^{\mathrm{a}}$ à $4 .^{\mathrm{a}}$ & ( ) Ensino Fundamental de $1^{\mathrm{a}}$ à $4 .^{\mathrm{a}}$ \\
\hline ( ) Ensino Fundamental de 5. à $8 .^{\mathrm{a}}$ & ( ) Ensino Fundamental de 5. à 8. ${ }^{a}$ \\
\hline ( ) Ensino Médio Incompleto & ( ) Ensino Médio Incompleto \\
\hline ( ) Ensino Médio Completo & ( ) Ensino Médio Completo \\
\hline ( ) Ensino Superior Incompleto & ( ) Ensino Superior Incompleto \\
\hline ( ) Ensino Superior Completo & ( ) Ensino Superior Completo \\
\hline ( ) Sem escolaridade & ( ) Sem escolaridade \\
\hline
\end{tabular}

$3^{\circ}$ Instituição onde cursa Contabilidade: ( ) Pública （ ) Privada

$4^{\circ}$ Qual o gênero? ( ) Masculino ( ) Feminino

$\mathbf{5}^{\mathbf{0}}$ Qual o período do curso? ( ) Iniciante （ ) Concluinte

$\mathbf{6}^{\mathbf{0}}$ Qual sua fonte principal de renda?

( ) Emprego Formal ( ) Emprego Informal ( ) Não trabalha

( ) Outros. Cite:

$7^{\mathbf{0}}$ Qual a sua faixa de renda mensal líquida pessoal?

( ) Até $\mathrm{R} \$ 678,00$ - ( ) $\mathrm{R} \$ 678,01$ até $\mathrm{R} \$ 1.000,00$ - ( ) $\mathrm{R} \$ 1.000,01$ até $\mathrm{R} \$ 1.500,00$ - ( ) $\mathrm{R} \$ 1.500,01$ até $\mathrm{R} \$$ $2.500,00$ - ( ) Acima de R $\$ 2.500,00$

$\mathbf{8}^{\circ}$ Qual sua faixa de renda mensal líquida familiar?

( ) Até $\mathrm{R} \$ 678,00$ - ( ) $\mathrm{R} \$ 678,01$ até $\mathrm{R} \$ 1.000,00$ - ( ) $\mathrm{R} \$ 1.000,01$ até $\mathrm{R} \$ 1.500,00$ - ( ) $\mathrm{R} \$ 1.500,01$ até $\mathrm{R} \$$ $2.500,00$ - ( ) $\mathrm{R} \$ 2.500,01$ até $\mathrm{R} \$ 4.000,00$

- ( ) Acima de $\mathrm{R} \$ 4.000,00$

$\mathbf{9}^{\circ}$ Onde você adquiriu a maior parte dos seus conhecimentos para gerir o seu dinheiro? Preencha as lacunas por ordem decrescente de importância (1 - Grande importância, 2 - Importante, 3 - Indiferente 4 - Pouca importância 5 - Não tem importância).

Em casa com a família __ De conversas com amigos __ Em aulas na faculdade De revistas, livros,

TV e o rádio De minha experiência prática.

$\mathbf{1 0}^{\mathbf{0}}$ Como você se sente a respeito dos seus conhecimentos para gerenciar seu próprio dinheiro?

( ) Nada seguro - Eu gostaria de possuir um nível muito melhor de educação financeira;

( ) Não muito seguro - Eu gostaria de saber um pouco mais sobre finanças;

( ) Razoavelmente seguro - Eu conheço algumas das coisas que eu precisaria saber sobre o assunto;

( ) Seguro - Eu conheço a maioria das coisas que eu precisaria saber sobre o assunto;

( ) Muito seguro - Eu possuo conhecimentos bastante amplos sobre finanças.

$\mathbf{1 1}^{\circ}$ Se você tivesse recursos para investir, sem ter um prazo definido para resgatar, com qual das alternativas abaixo você mais se identificaria como aplicador?

( ) Ações, pois me agrada a possibilidade de altos ganhos, mesmo sabendo do risco elevado de perdas;

( ) Fundos de investimento de risco médio, pois quero um rendimento razoável, ainda que com algum risco;

( ) Poupança, pois priorizo a segurança em relação ao rendimento;

( )Bens (Carro, moto, imóvel...), pois a segurança para mim é a coisa mais importante.

$\mathbf{1 2}^{\mathbf{2}}$ Dirceu e Roberto são jovens que têm o mesmo salário. Ambos desejam comprar um carro no valor de R\$ 10.000,00. Quem pagou mais pelo bem?

( ) Dirceu, que comprou hoje, financiando o saldo devedor por 24 meses;

( ) Roberto, que preferiu poupar por 15 meses, mas comprou o carro à vista.

$\mathbf{1 3}^{\circ}$ Se tivesse que tomar a mesma decisão, qual a melhor alternativa, na sua visão?

( ) Ter o carro imediatamente e pagar por ele durante 24 meses, como fez Dirceu;

( ) Poupar por 15 meses para comprá-lo à vista, sem dívida, como fez Roberto;

$\mathbf{1 4}^{\mathbf{0}}$ Você tem algum tipo de dívida (empréstimos, financiamentos, rotativo do cartão)?

( ) Sim, tenho, mas trata-se de financiamento de longo prazo, cuja prestação eu sempre procuro pagar em dia;

( ) Sim, tenho, mas não sei bem quando nem como irei pagá-las;

R. Cont. Ufba, Salvador-Ba, v. 9, n. 3, p. 103 - 117, set-dez 2015 
( ) Sim, mas vou pagá-las em pouco tempo, já que tomei o cuidado de calcular na ponta do lápis como e quando iria quitá-las;

( ) Não tenho dívidas pessoais. Sempre faço o planejamento necessário para comprar à vista e com desconto.

$\mathbf{1 5}^{\circ}$ Você planeja suas compras com antecedência?

( ) Sempre ( ) Quase sempre ( ) As vezes ( ) Quase nunca ( ) Nunca

$\mathbf{1 6}^{\mathbf{O}}$ Ao fazer compras, você se preocupa com a qualidade e preço dos produtos?

( ) Sempre ( ) Quase sempre ( ) As vezes ( ) Quase nunca ( ) Nunca

Muito obrigada pela colaboração. É garantido o anonimato da pesquisa.

R. Cont. Ufba, Salvador-Ba, v. 9, n. 3, p. 103 - 117, set-dez 2015 